\title{
Supervision as prevention and support to teachers in inclusive education
}

\author{
Petra Potměšilová, Miloň Potměšil, \\ Marcela Fojtíková Roubalová
}

\begin{abstract}
The presented research was focused on the field of sentiments, attitudes and concerns of educators potentially working with pupils with impairment under inclusive settings.

This study was aimed at discovering whether the above stated parameters change after achieving qualification in special needs education. The results of research encompassing a period of two years aimed at describing a group of 794 educators from the point of view of the development of their attitudes, opinions and concerns while being focused on the process of inclusion. In accordance with the obtained results, supervision as a special psychological support is badly needed.
\end{abstract}

Key words: inclusion, attitudes, sentiments, education, pupils with impairment, methodology of teaching, overloading, stress, supervision, teacher. 


\section{Introduction}

\section{Notions of the first part research}

In regard to the fact that the presented research is directed to the field of special needs education, which represents, in the context of pedagogy and education, a very good example of an inter-field approach, the respective terminology was defined at first. It is necessary to mention normalization and inclusion. Probably the most fundamental statement in relation to upbringing and education was expressed in the Salamanca statement (1994) by the representatives of 92 UNESCO member countries in their declaration. This declaration speaks about tendencies which lead to elimination of discriminating attitudes through establishing open inclusive schools and, subsequently, through creating social consciousness which is also directed towards the principles of inclusion. The main issue discussed therein was education, and that is why the principal theme characteristic for the entire recent process was: "Education for all". A significant attribute was the notion of normalization, which is closely linked with the requirement for adjustments of conditions ensuring the "normal" life of people with mental disabilities. It was first introduced by the Danish lawyer Niels Erik Bank-Mikkelsen (1999). Adjustment - normalization refers to common every-day activities, involvement in the every-day life of society in the extent of being acceptable to each particular person. This concept then also gave rise to a similar view of the process of education (Gilbert \& Hart, 1990) and socialization of people with other types of disadvantages.

The essential term for this study is inclusion. The concept of inclusion follows the basic human rights, which - if they are to be abided by - may not leave out the group of people with special needs (Meijer, 2001). Inclusion thus, for our purposes, represents a set of conditions, which, if they operate mutually/bilaterally, provide handicapped people with an approach by the majority of society focusing on developing their potentials in individual sectors and supporting their abilities so that they become fully functional tools for a maximum independent life within the society. The fundamental difference lies in the fact that pedagogy, in the event of inclusion, operates with human rights. To simplify things, it may be stated that a school must be conformed to a child, not the child to the school (Groma, 2008). Inclusive pedagogy views children or pupils from such a position, which does not distinguish the differences caused by the abovementioned reasons, but it is supposed to work with a group where each individual has his/her own particular needs compared with Milovanovitch (2009).

The aims of the educational process are stipulated in the national, and later, in the school educational curriculum and, if need be, in an individualized plan serving as a tool corresponding to specific needs. Within the framework of general pedagogy, modern educational philosophy views, the current trend as being comprehensive. In this respect, e. g. R. Barrow and R. Woods (2006) mention on pages 94-95 the requirements for educators and teachers who implement the process of education and characterize 
it as "rational" and explain it further from the point of view of the modern conception of pedagogy and the necessary competencies of teachers. Competencies of teachers towards handicapped children and pupils are dealt with in a publication by A.W. Brue and L. Wilmshurst (2005) who list the competencies of educators essential for work with children and pupils with various types of handicap and then also the special needs in education. K. Hull (2002) offers specific characteristics of inclusion and inclusive education and sees the following assumptions as fundamental (p. 13):

- Handicapped children may take part in the same educational programs as their contemporaries.

- They can visit an environment which reflects their real age.

- They can, if need be, use an individual approach in the form of an individualized educational plan (IEP).

- They have the right to receive support from the special needs education, according to their needs.

General educational work focused on children and pupils, both handicapped and intact, naturally demands the readiness and competencies of the respective pedagogical personnel. Hájková (2005) as well as Blake, Smeyers, Smith, Standish (2006) defines the professional competencies of a teacher as a set of prerequisites for performing teaching activities, and also as a capacity to act intelligently in situations which are constantly new and unique, with the aim of finding a suitable on-the-spot response. If a teacher possesses these abilities to evaluate and make decisions, he/she is apt to choose suited responses in situations which can be completely new and unexpected - there is more about this from Lambe (2007). With respect to the fact that our aim is not to present specific competencies expected of teachers who are specialized in the education of handicapped children (from the point of view of the type), by taking into account the specificities of particular handicap. The research results of studies conducted by D. J. Bjarnason (2005) in Iceland indicated a close cohesion between the change of conditions within the transformation of the traditional approaches to the form of inclusive education and their reflection in the preparation of future educators. From the point of view of the monitored competencies and attitudes, the author is clearly speaking about "... changed general educator's roles in the face of growing student diversity".

\section{The aim of the research}

The study (the complete research report was published as an article: Potměšil (2011) was aimed at describing a group of 794 educators from the point of view of the development of their attitudes, opinions and concerns focused on the process of inclusion. In accordance with the acquired results one of the supportive form will be designed the supervision. 


\section{Method}

Data was gathered from in-service teachers working in different parts of the Czech Republic. All the participants took part in the research as volunteers. The total data set comprised of 638 completed questionnaires. The data was collected between 2009 and 2011 using the questionnaire which was used by Loreman et al. (2007). A statistical analysis was conducted on the data employing a principal component analysis.

\section{Analysis of the acquired data}

The research involved 794 informants from all over the Czech Republic. (22.4\% males, $77.6 \%$ females). The age of informants oscillated by $32.8 \%$ up to the age of 29 years, while $37.8 \%$ fell into the category of 30-39 years and $29.4 \%$ above the age of 40 .

The education level of our informants was as follows: $59.5 \%$ informants completed their secondary schools education, $24.6 \%$ informants completed their study with a Bachelor's degree and $15.9 \%$ informants completed their study of a Master's degree. A mere $0.5 \%$ of the informants had completed their doctorate program (Ph.D.).

In order to conduct further analysis, all the items of the questionnaire were divided into two groups:

\section{Labor input and stress}

That group of statements referring to labor input and stress when teachers work with students with special needs under the conditions of inclusive education should also be considered, and then summed up with the following from the acquired data:

- More than $90 \%$ of the informants of both the waves do not have a negative relationship towards handicapped people.

- Approximately $70 \%$ of the informants in both the waves believe that the presence of a pupil with special educational needs in a classroom shall increase their work load.

- $58 \%$ of the informants in both the waves expressed their misgivings of sufficient support for inclusive education on the part of professional workplaces.

- The level of one's own competencies was regarded as insufficient by $58.9 \%$ of the informants.

- More than $36.4 \%$ of the informants voiced their concerns that it was not possible to pay enough attention to a pupil with specific educational needs.

- The presence of a handicapped pupil was regarded as a great source of stress by $29 \%$ of the informants. 


\section{The education process and its management}

In this set of statements there were answers regarding the process of inclusive education and opinions of educators about managing of their load.

- The statements focusing on the presence of pupils with impaired communication competencies and the possible presence of an assistant were evaluated positively by over $90 \%$ of informants.

- Almost $70 \%$ of the informants negated the possibility to incorporate pupils with aggressive behavior into a standard classroom in the form of inclusive education.

- A shift in the evaluation of effectiveness and acceptability of work according to an individualized plan was demonstrated as $76.5 \%$.

- Concerns about the application of special communication techniques were expressed by $52.7 \%$ of the informants.

- About $70 \%$ informants did not show any concerns about working with pupils with ADHD disorders.

- The presence of pupils who are constantly unsuccessful at school results is unthinkable for $52.7 \%$ of the informants.

- Problems with the acceptance of handicapped pupils by intact classmates were expected by approximately $40 \%$ of the informants.

Conclusions relating to the labour input and stress and the process of education and its management:

The informants of the research relate positively to handicapped people, and as more than half of them are concerned about the insufficient support for inclusive education from professional workplaces, they therefore realize higher work load but the implementation of inclusive education does not seem to bring about any increased stress level for them. A half of the informants senses a lack of competencies and, consequently, also has concerns about whether they will not be able to pay sufficient attention to pupils with special needs.

Furthermore, the informants showed willingness to accept a pupil with specific needs and possibly even co-operation with an assistant. Work based on an individualized plan is accepted by the informants and is regarded beneficial. They, however, refuse to work with students with behavioural disorders in the extent of aggressiveness as constantly unsuccessful, whereas working with pupils with attention disorders does not seem to cause any concerns. A part of the informants (40\%) expressed their concerns about the acceptance of pupils with specific needs into the team of an intact group in a classroom.

In accordance with answers concerning sentiments, attitudes and concerns of educators when working under the conditions of inclusion, it can be stated that the sample of informants addressed in the presented research demonstrated conscious willingness 
to co-operate on projects of individual inclusion. They feel, however, concerns on key items about the lack of professional competencies and support and effectiveness of such educational work.

The research, which is described below, is based on those results obtained before. The finding that more than $90 \%$ of the addressed educators do not have a negative attitude towards disabled individuals was essential with respect to further research; however, a half of the respondents expressed their concerns in relation to the presence of a pupil with special educational needs at their primary schools. These concerns were clearly defined by the educators as associated with their fear of having insufficient skills and of apparently not receiving adequate support from professional institutions.

Based on the above, it might be concluded that with an adequate and well-functioning professional base, educators need not be concerned about the inclusion of pupils with special educational needs atnormal primary schools. As it is stated in Hull, Goldhaber \& Capone (2002) or Gilbert \& Hart (1990).

One of the fundamental factors facilitating effective expert support to educators should be supervision. Supervision constitutes standard support, which is utilised by psychologists and psychotherapists within their everyday work. Nevertheless, current legislation fails to determine any kind of supervision with respect to primary school teachers, as well as pupils with special educational needs. The only exception are the Methodical Guidelines for Rendering Supervision in Educational Facilities for the Provision of Institutional or Juvenile Correctional Education and in Educational Facilities for the Provision of Preventive Educational Care, which lay down the definition of supervision, characterize supervision in such school facilities, and determine the function of supervisors and their required education. These guidelines were already issued (Předpisy 2012).

According to Hawkins (2004, p. 59), Hess defines supervision as a quintessential interpersonal interaction with the general goal that one person, the supervisor, meets with another, the supervisee, in order to make the latter more effective in helping people.

Supervision is a distinct professional activity in which education and training aimed at developing science-informed practice are facilitated through a collaborative interpersonal process (Falender, Shafranske, p. 3).

Rue and Byars (1990) define supervision as a first level of management in an organization.

The results indicated herein are based on a survey that is currently in progress. As of May 2012, 140 relevant questionnaires have been collected and recorded from the total number of 165 respondents addressed so far. A total of 25 questionnaires have been discarded as they contained incomplete answers to some of the questions or lacked basic information required for the further processing of the survey results. 
The questionnaire comprises twelve questions. It should be noted that multiple options could be selected with some of the questions and the sum of the answers provided therefore does not correspond to the number of respondents. For the purposes of this text, the first three questions, in which the respondents provided basic information about themselves (sex, age and years of practical experience) were chosen and further processed along with two additional questions:

- $\quad$ No. 5: What do I understand under the term "supervision"?

- $\quad$ No. 7: I would welcome supervision...

The target group of respondents is built by pedagogical staff. Pursuant to Section 2 of Act No. 563/2004 Coll., on Pedagogical Staff, within the wording of the amending Act No. 159/2010 Coll., a pedagogical worker is a person who performs direct teaching, direct educational, direct special educational, or direct pedagogical and psychological activities by directly affecting the learner and thereby effectuates education and edification pursuant to a special legal regulation; who is an employee of a legal entity carrying out the activities of a school or an employee of the state, or the headmaster/headmistress of a school where such a person is not in a labour-law relation with a legal entity carrying out the activities of a school or is not an employee of the state. A pedagogical worker is also an employee who performs direct pedagogical activities in social care facilities.

\section{Respondent division according to sex}

From the total of 140 respondents addressed so far, 125 are women, i.e. $89 \%$. The composition of the research sample corresponds to the current composition of pedagogical staff in the Czech Republic.

\section{Respondent age}

The age of the respondents ranges between 21 and 55 years. The largest number of respondents is aged between 31 to 40 years, or is under 30 years of age.

\section{Respondent length of practical experience}

Almost half of the respondents (48\%) have less than 5 years of practical experience. From the total number of 67 respondents, 21 respondents had only a year of pedagogical practical experience. The longest practical experience was 34 years.

With a view to the fact that the research is still in progress, the above indicated data currently serve only for information purposes. After all data are collected, the mutual correlations between the individual questions will be determined (i.e. relationship 
between the length of practical experience and the need for supervision, relationship between age and the need for supervision, etc.).

\section{What do I understand under the term "supervision"?}

The purpose of this question was to ascertain how the addressed respondents understand the term "supervision", what they envisage under this term. The respondents could select multiple answers (tab. No. 1).

Table 1: Understanding "supervision"

\begin{tabular}{|c|c|c|}
\hline 1. Form of control or inspection & 18 & $7 \%$ \\
\hline 2. Form of assistance or support provided to me in my personal life & 33 & $13 \%$ \\
\hline 3. Form of assistance or support provided to me in my professional life & 92 & $35 \%$ \\
\hline 4. Form of assistance and support provided when working with pupils and clients & 88 & $34 \%$ \\
\hline 5. Form of support provided to managerial staff & 30 & $11 \%$ \\
\hline 6. I cannot think of anything & 0 & $0 \%$ \\
\hline Total & 261 & $100 \%$ \\
\hline
\end{tabular}

The largest number of answers was registered with options Nos. 3 and 4, which implies that $35 \%, 34 \%$ respectively, of all the answers perceive supervision as providing support in professional life and/or when working with pupils or clients.

\section{I would welcome supervision...}

Question No. 7 is aimed at determining the direction of the conceivable need for supervision among pedagogical staff. The respondents could choose from 5 options and they could provide multiple answers (tab. No. 2).

Table 2: Welcome supervision as...

\begin{tabular}{|l|r|r|}
\hline 1. As support when working with specific clients & 72 & $26 \%$ \\
\hline 2. As support in relation to my development in my personal life & 33 & $12 \%$ \\
\hline 3. As support in relation to my development in my professional life & 88 & $32 \%$ \\
\hline 4. As support ensuring the effective functioning of the work team & 68 & $24 \%$ \\
\hline 5. As support within managerial work & 18 & $6 \%$ \\
\hline Total & 279 & $100 \%$ \\
\hline
\end{tabular}


The largest number of answers was registered with option No. 3, namely $32 \%$ of the total number of 279 answers. The second most frequently selected answer was option No. 1 (26\%), followed by option No. 4 (24\%).

\section{Discussion}

The above shown tables and diagrams clearly imply that 92 answers of the respondents to the question "What do I understand under the term 'supervision'?" consider supervision as support in professional life. Eighty eight answers characterize supervision as assistance and support when working with clients. Based on these figures and percentages, it might be concluded that most of the respondents perceive supervision as possible professional assistance in relation to working with clients. This fact is quite significant as regards the planned practical use of supervision in pedagogical practice as the educators themselves accept one of the forms of supervision.

When comparing the above specified results with the data collected for question No. 7: I would welcome supervision, we may say that the major part of the provided answers involved support when working with clients or support in professional life, i. e. 88 answers, 72 respectively.

Referring to the results of hypotheses have been developed and performed the statistical analysis of the relationship of the above items.

$\mathrm{H}(0)$ : The fact that teachers receive support in the supervision of their professional life is not statistically dependent on the expressed need for supervision.

$H(A)$ : The fact that teachers receive support in the supervision of their professional life is statistically dependent on the expressed need for supervision.

PivotTable 3

\begin{tabular}{|c|c|c|c|}
\hline Support in professional life & 0 & 1 & Total \\
\hline 0 & 29 & 19 & 48 \\
\hline 1 & 23 & 69 & 92 \\
\hline Total & 52 & 88 & 140 \\
\hline
\end{tabular}

Based on data in a PivotTable (tab. No. 3) test criterion was calculated ( $\left.X^{2} 294.8112929\right)$, which is larger than the critical value at significance level of 0.01 ( $X^{2} 0.01$ (1) 6.634896712). Given that the calculated test criterion is higher than the critical value of the refuse consent for the null hypothesis and could be accepted the alternative hypothesis:

The fact that teachers understand supervision as an aid in their professional lives and that would receive help in the supervision of their professional life shows the statistically significant association. 
H0: $\quad$ The fact that teachers understand supervision as support when working with clients and that they would welcome supervision as support while working with clients, there is no statistically significant association.

HA: The fact that teachers understand supervision as support when working with clients and that they would welcome supervision as support while working with clients, there is statistically significant association.

\section{PivotTable 4}

\begin{tabular}{|c|c|c|c|}
\hline Support in working with clients & 0 & 1 & Total \\
\hline 0 & 37 & 15 & 52 \\
\hline 1 & 31 & 57 & 88 \\
\hline Total & 68 & 72 & 140 \\
\hline
\end{tabular}

Based on data in a PivotTable (tab. No. 4) test criterion was calculated ( $\left.x^{2} 80.82491517\right)$, which is larger than the critical value at significance level of 0.01 ( $x^{2} 0.01$ (1) 6.634896712). Since the calculated test criterion is higher than the critical value, the null hypothesis it can be refused and the alternative hypothesis can be accepted.

The fact that teachers understand supervision as support when working with clients and that supervision is seen as support when working with clients is a statistically significant association.

In relation to question No. 7: I would welcome supervision; the option concerning support for the team work is among very frequent answers, i.e. 68 in aggregate.

In addition to support in their professional life, pedagogical workers would also welcome support aimed at effective functioning of their team work.

The frequency of two additional options is also significant with regard to planning supervisory activities for educational professionals. The first is support in personal life. A total of 33 respondents perceive supervision as providing support in their personal life and 33 respondents would welcome such support in practice.

Based on these results, research hypotheses were established and a statistical verification of the relationship of the above items using $\mathrm{chi}^{2}$ test of goodness of fit performed:

H0: $\quad$ The fact that teachers understand supervision as support in private live and that they would welcome supervision as support for their private life, does not bring statistically significant association.

HA: The fact that teachers understand supervision as support in private live and that they would welcome supervision as support for their private life, brings statistically significant association. 


\section{PivotTable 5}

\begin{tabular}{|c|c|c|c|}
\hline Support in personal life & 0 & 1 & Total \\
\hline 0 & 94 & 13 & 107 \\
\hline 1 & 13 & 20 & 33 \\
\hline Total & 107 & 33 & 140 \\
\hline
\end{tabular}

Based on data in a PivotTable (Tab. No. 5) test criterion was calculated ( $x^{2}$ 32.87249134), which is larger than the critical value at significance level of 0.01 ( $X^{2} 0.01$ (1) 6.634896712). Given that calculated test criterion is higher than the critical value of the refuse consent for the null hypothesis and that is why the alternative hypothesis is accepted:

The fact that teachers understand supervision as support in their personal life and that supervision would is welcomed as support in teachers personal life appreciate the statistically significant association.

The second one is the perception of supervision as an inspection. This option was selected by 18 respondents. Even if this number may seem insignificant when compared to the total number of respondents (140), it does suggest that, in practice, pedagogical workers have certain concerns of being under control. These concerns should be taken into account when developing a supervision program for pedagogical staff. Concerns in relation to supervision may appear among some pedagogical workers as supervision is commonly associated with control and inspections.

The frequency of the option involving supervision of managerial staff in connection with both the questions is also quite interesting. It suggests that pedagogical workers consider this type of supervision as important in relation to their work.

Based on this fact, research hypotheses were developed and statistical verification of the relationship of the above items using chi2 test of goodness of fit implemented: $\mathrm{HO}$ : The fact that teachers understand supervision as support in private live and that they would welcome supervision as support for managing work and that supervision does not bring statistically significant association.

HA: The fact that teachers understand supervision as support in private live and that they would welcome supervision as support for managing work and that supervision brings statistically significant association.

PivotTable 6

\begin{tabular}{|c|r|r|r|}
\hline \multicolumn{1}{|c|}{ Support in managing work } & 0 & 1 & Total \\
\hline 0 & 100 & 10 & 110 \\
\hline 1 & 22 & 8 & 30 \\
\hline Total & 122 & 18 & 140 \\
\hline
\end{tabular}


Based on data in a PivotTable (tab. No. 6) test criterion was calculated $\left(X^{2} 6.498868466\right)$, which is smaller than the critical value at significance level of $0.01\left(x^{2} 0.01\right.$ (1) 6.634896712 ). Given that calculated test criterion is less than the critical value, which is why it cannot be rejected as a null hypothesis.

The fact that teachers understand supervision as support for managing work and that supervision would like support in management welcomed does not bring statistically significant association.

Supervision provides the supervisees with the opportunity to see the particular situation from a different perspective, and thereby allows them to take an adequate stand. With regard to the fact that supervision has not yet become a standard part of pedagogical work, as well as the concerns expressed by the educators, our next aim is to create a supervision program for this target group.

The above specified results imply that pedagogical staff is interested in case, team as well as managerial supervision. In addition to these three types, there is also a need to expand supervision to cover the personal or private area. At first sight, it may seem that this area does not fall within the scope of supervision. However, our own practical experience tells us that if an individual is not content in his or her personal life, it may hugely influence his or her professional life.

Based on the individual types of supervision, a specific draft plan of supervisory activities will be drawn up and it will implement both the individual and group forms of supervision. The work itself will be grounded on interviews, on role playing with the aid model situations and on the use of expressive therapy, in particular art therapy.

As a general conclusion of the first presented part, it is possible to make a statement that teachers who are working under inclusive educational settings are forming a group for which psychological supervision is badly needed.

\section{Reference}

Barrow, R., Woods, R. (2006) An Introduction to Philosophy of Education. 4th edition, Routledge. Blake, N., Smeyers, P., Smith, R., Standish, P. (2006) Philosphy of Education. 5th edition, Malden: Blackwell Publishing.

Bjarnason, D. (2005) Disability Studies and Their Importance for Special Education Professionals. Nordisk Pedagogik, 25, 339-356.

Brue, A. W., Wilmshurst, L. (2005) A Parent's Guide to Special Education. New York: AMACOM.

Falender, C. A., Shafranske, E. P. (2004) Clinical Supervision: A Competency-Based Approach. 1st ed. Washington: American Psychological Association. 348 pp.

Flynn, R. J., Lemay, R. A. (1999) (Eds.) A Quarter-century of Normalization and Social Role of Valorization: Evaluation and Impact. Ottawa: University of Ottawa Press.

Forlin, Ch. (2006) Inclusive Education in Australia Ten Years After Salamanca. European Journal Of Psychology Of Education, XXI, 3, 265-277.

Hawkins, P., Shonet, R. (2004) Supervize v pomáhajících profesích. Praha: Portál, 202 pp. 
Hull, K., Goldhaber, J., Capone, A. (2002) Opening Doors. Boston: Houhgton Miffin Comp.

Gilbert, C. and Hart, M. (1990). Towards Integration: Special Needs in an Ordinary School. London: Kogan

Lambe, J. (2007) Northern Ireland Students Teachers' Changing Attitudes Towards Inclusive Education During Initial Teacher Training. International Journal of Special Education, 22, 1, 59-71.

Loreman, T., Earle, Ch., Sharma, U., Forlin, Ch. 2006. Pre-service Teachers'Attitudes, Concerns and Sentiments about Inclusive Education: an International Comparison of the Novice pre-service teachers. International Journal of Special Education, 21, 2, 80-93.

Loreman, T., Earle, Ch., Sharma, U., Forlin, Ch. (2007) The Development of an Instrument for Measuring Pre-service Teachers' Sentiments, Attitudes, and Concerns about Inclusive Education. International Journal of Special Education, 22, 2, 150-160.

Meijer, J. W. Ed. (2001) Inclusive Education and Effective Classroom Practices. Odsense: Europe - an Agency for Development in Special Needs Education. Milovanovitch, M. (2009) Teacher Education for Diversity. ERI SEE Zagreb.

Potmesil, M. The Sentiments, Attitudes and Concerns of Educators When Working Under the Conditions of Inclusion. Annales Universitatis Paedagogicae Cracoviensis Studia Psychologica IV. WN Uniwersytetu Pedagogicznego. Kraków: 2011. pp. 71-85.

Rue, L.W. A Byars, L. L. (1990) Instructor's Manual: Supervision: Key Link to Productivity. 3. vyd. Homewood: Irwin, 208 pp.

Sociální programy. [online] cit. 24. 5. 2012 From: http://www.msmt.cz/socialni-programy/metodicky-pokyn-k-poskytovani-supervize?highlightWords=supervize

Předpisy. [online] cit. 24. 5. 2012 From: http://aplikace.msmt.cz/Predpisy1/sb190-04.pdf

Valeo, A. (2008) Inclusive Education Support Systems Teacher and Administrator View. International journal of Special Education, 23, 2, 8-16.

\section{Contact:}

PhDr. Mgr. Petra Potměšilová, Ph.D.

Mgr. Marcela Fojtíková Roubalová

Department of Christian Education

Sts. Cyril and Methodius Faculty of Theology

Palacký University Olomouc

Univerzitní 22

77111 Olomouc, Czech Republic

E-mail: petra.potmesilova@upol.cz; roubalova.marcela@seznam.cz

doc. PhDr. PaedDr. Miloň Potměšil, Ph.D.

Department of Special Education

Faculty of Education

Palacky University Olomouc

Žižkovo nám. 5

77140 Olomouc, Czech Republic

E-mail:mvpotmesil@gmail.com 